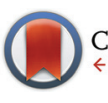

CrossMark \& click for updates

Cite this: Polym. Chem., 2015, 6 , 3617

Received 19th March 2015,

Accepted 30th March 2015

DOI: $10.1039 / \mathrm{c} 5 \mathrm{py} 00404 \mathrm{~g}$

www.rsc.org/polymers

\title{
Vinyl ferrocenyl glycidyl ether: an unprotected orthogonal ferrocene monomer for anionic and radical polymerization $\uparrow$
}

\begin{abstract}
Arda Alkan, ${ }^{a, b}$ Laura Thomi, ${ }^{a}$ Tassilo Gleede ${ }^{b}$ and Frederik R. Wurm ${ }^{\star a}$
The first orthogonal ferrocene monomer, vinyl ferrocenyl glycidyl ether (VfcGE), for both anionic and radical polymerization - without the need of a protection group - is presented. Anionic ring-opening copolymerization of $\mathrm{VfCGE}$ and ethylene oxide (EO) generates stimuli-responsive, multifunctional poly [(vinyl ferrocenyl glycidyl ether)-co-(ethylene oxide)] (P[VfCGE-CO-EO]) copolymers (molecular weights of ca. $7500 \mathrm{~g} \mathrm{~mol}^{-1}$ and low molecular weight dispersities $(\Theta \leq 1.14)$ ). The amount of the equimolar ferrocenyl and vinyl groups are controlled by the comonomer ratio up to 15.4 mol\% VfcGE. The pendant vinyl groups of P[VfcGE-CO-EO] were post-modified with 3-mercaptopropionic acid via thiol-ene chemistry. The EO copolymers exhibit temperature-, redox-, and $\mathrm{pH}$-responsive behavior in water depending on the polymers' microstructure. Free radical polymerization of VfcGE leads to polyalkylene:(vinyl ferrocenyl glycidyl ether) with pendant epoxide side chains at each ferrocene unit. The resulting polymer was used to generate redox-responsive protein nanoparticles with bovine serum albumin (BSA) by nucleophilic ringopening of the pendant epoxides.
\end{abstract}

\section{Introduction}

Metallocene-containing polymers combine peculiar physical and chemical properties for several materials science applications. In the family of metallocenes, ferrocene (fc) is probably the most interesting compound, since it can be oxidized reversibly to the ferrocenium species (Fe(III)) and iron redox processes play an important role in living organisms. Both states exhibit high stability with ferrocene (Fe(II)) being very stable as an 18e complex. To date, fc-containing compounds are used as polyelectrolytes, ${ }^{1}$ electroactive materials in amperometric glucose sensors ${ }^{2-4}$ and catalysts ${ }^{5-7}$ in fuel for the oxidation of soot. ${ }^{8}$ Fc-based materials are also used in responsive elastomeric opal films, ${ }^{9}$ for the redox responsive assembly and disassembly of nanotubes ${ }^{10}$ and in colour-tunable fluorescent multiblock micelles. ${ }^{11}$ Furthermore, recently biomedical applications became an important field for the utilization of metallocene-containing materials. ${ }^{12,13}$

\footnotetext{
${ }^{a}$ Max Planck Institute for Polymer Research (MPIP), Ackermannweg 10, 55128 Mainz, Germany.E-mail:wurm@mpip-mainz.mpg.de

${ }^{b}$ Institute of Organic Chemistry, Johannes Gutenberg-Universität Mainz (JGU), Duesbergweg 10-14, 55099 Mainz, Germany

$\dagger$ Electronic supplementary information (ESI) available: Additional characterization data: ${ }^{13} \mathrm{C},{ }^{13} \mathrm{C}$ DEPT, HSQC, HMBC and COSY NMR spectra of VfcGE (3). ${ }^{1} \mathrm{H}$ NMR spectrum of $\mathrm{P}[\mathrm{EO}-\mathrm{co}-\mathrm{VfcGE}]$ (P2). MALDI ToF mass spectrum of $\mathrm{P}$ [EO-co-VfcGE] (P3). ${ }^{1} \mathrm{H}$ NMR and MALDI ToF mass spectra of polyalkylene: VfcGE (P1). See DOI: 10.1039/c5py00404g
}

Ferrocene itself and its low molecular weight derivatives find limited application in materials science due to high crystallinity or low vapor pressure. The incorporation of fc into polymers allows usage of the organometallic properties. ${ }^{14} \mathrm{Fc}$ can be incorporated either as side chains or in the polymer backbone. Besides the famous main-chain polyferrocenyl silanes ${ }^{15-17}$ several examples of polymers with ferrocenebased side chains have been reported. The most popular monomer, which is known since $1955,{ }^{18}$ is probably vinyl ferrocene (Vfc, 1, Fig. 1) that can be polymerized via radical or anionic polymerization mechanisms. Also, (meth)acrylatebased side-chain ferrocene-containing monomers have been studied intensely. ${ }^{19,20}$ In 2013, we introduced the first fccontaining epoxide monomer, i.e. ferrocene glycidyl ether (fcGE, 2, Fig. 1) for oxyanionic polymerization..$^{21} 2$ was homopolymerized, but also copolymerized with ethylene oxide (EO), the latter produces water-soluble fc-containing poly(ethylene glycol)s which may find useful applications in the biomedical

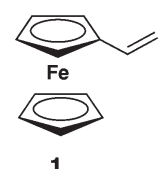

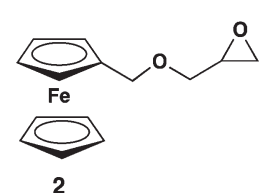

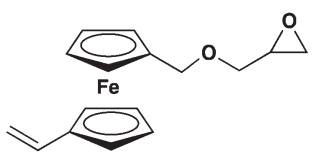

3
Fig. 1 Side-chain ferrocene monomers. 
field or as stabilizers. From kinetic studies the anionic copolymerization of sterically demanding 2 and EO was found to be random; ${ }^{21}$ interestingly, despite the bulky fc-side group, no gradient copolymers were generated under these conditions. More recently, we have expanded the use of 2 and synthesized multifunctional fc-containing polyethers by -again randomcopolymerization with allyl glycidyl ether, which was carried out in bulk at $100{ }^{\circ} \mathrm{C}$ and monitored in situ via ${ }^{13} \mathrm{C}$ NMR spectroscopy. $^{22}$

Polyfunctional, stimuli-responsive materials are a growing field in modern materials and bio-related science. Nature uses the principle of polyvalency for receptor-mediated processes, for example. In polymer science, polyvalency is typically achieved by the polymerization of a functional monomer or copolymerization of several monomers. Especially monomers with functional groups, which do not have to be protected during the polymerization, are of high interest, since protection and deprotection steps are spared. Orthogonal monomers with two different polymerizable groups are also very interesting, since they make the copolymerization of several monomers (with often unwanted copolymerization behavior) redundant. But especially monomers with two different polymerizable groups, whereas the second group acts as an unprotected functionality, are rarely found to date..$^{23-25}$ The reported bifunctional monomers to date rely on rather simple monomer structures without additional properties. ${ }^{23}$

The current work presents the first orthogonal metallocene monomer carrying both an epoxide and a vinyl group, viz. vinyl ferrocenyl glycidyl ether (VfcGE (3), Fig. 1). 3 differs significantly from all other ferrocene side-chain monomers reported so far, since it is designed for both radical or anionic ring-opening (co-)polymerization ${ }^{26}$ and the organometallic polymers carry multiple reactive groups for postpolymerization modification. Both selective anionic and radical polymerization of $\mathbf{3}$ are investigated in detail and the copolymerization with ethylene oxide to water-soluble, organometallic, and polyfunctional poly(ethylene glycol)s is presented. Subsequent postpolymerization modification of the pendant epoxide or vinyl groups was carried out. The polyethers are -in addition to their chemical polyvalency- further multi-stimuli responsive with respect to solubility in water, depending on $\mathrm{pH}$, redoxpotential and side-chain functionality.

\section{Results and discussion}

\section{Monomer and polymer synthesis}

Fc-containing (co)polymers with polyether backbone as well as polyalkylene backbone are of high interest for multi stimuliresponsive materials. In this study we have developed an orthogonal ferrocene monomer (VfcGE, 3), which can be polymerized via two different polymerization techniques: radical and anionic polymerization. VfcGE opens new possibilities to fast access to ferrocene-containing multifunctional polyethers as well as polyalkylenes with ferrocene units bearing reactive epoxides (Scheme 1). The free radical polymerization of VfcGE

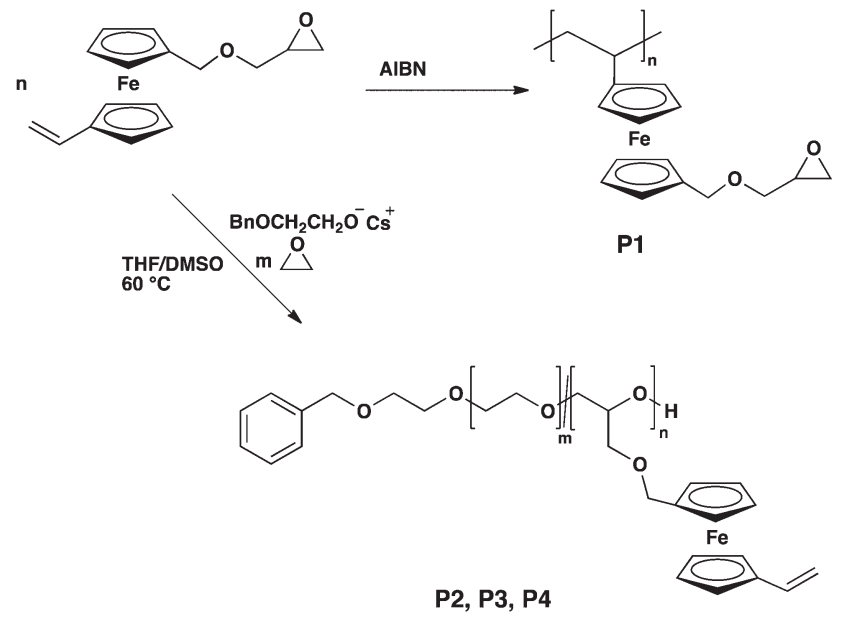

Scheme 1 Synthetic protocol for free radical and anionic copolymerization of VfcGE and EO.

leads to a polyalkylene structure whereas the anionic ringopening polymerization leads to a polyether backbone.

An additional advantage of VfcGE is the multifunctionality of the resulting polymers. In the case of polyalkylene:VfcGE each ferrocene unit bears an epoxide functionality which for example can be addressed with amine groups, whereby in the case of $\mathrm{P}[\mathrm{VfcGE}-\mathrm{co}-\mathrm{EO}]$, i.e. polyethers, each ferrocene unit carries vinyl groups which can be post-modified with various chemistries.

The monomer (3) was synthesized in a four-step protocol (Scheme 2), starting with the dilithiation of ferrocene to generate ferrocene-1,1'-dicarbaldehyde (4). In the second step, one of the aldehyde groups was transformed into a vinyl group by a Wittig reaction. ${ }^{27}$ The resulting compound, 1-vinyl-1'-carbox-
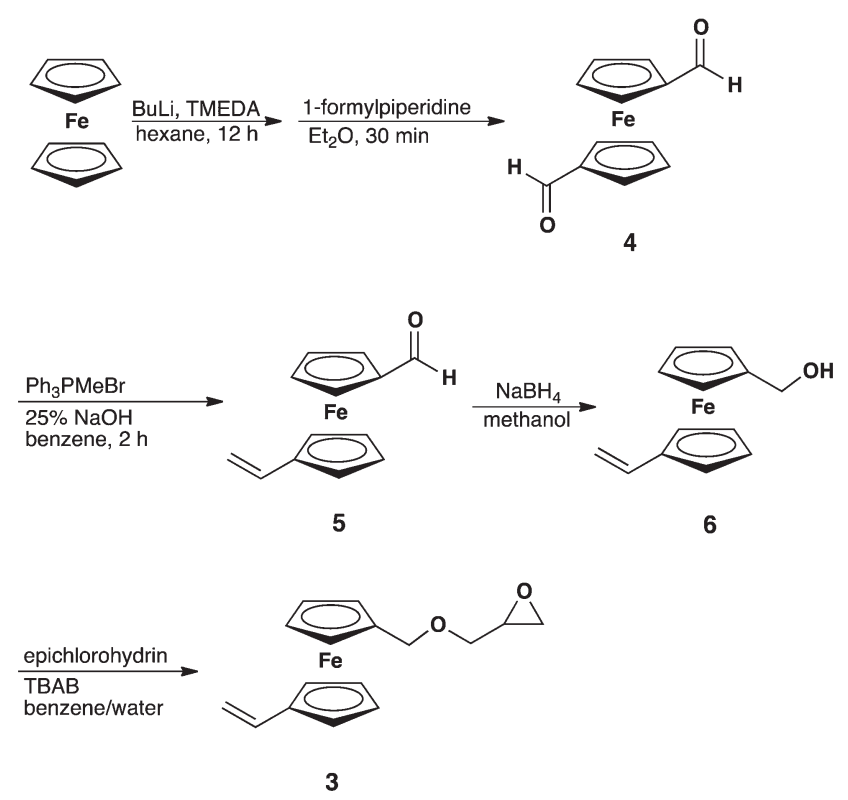

Scheme 2 Synthesis route to the orthogonal monomer vinyl ferrocenyl glycidyl ether (VfCGE, 3). 


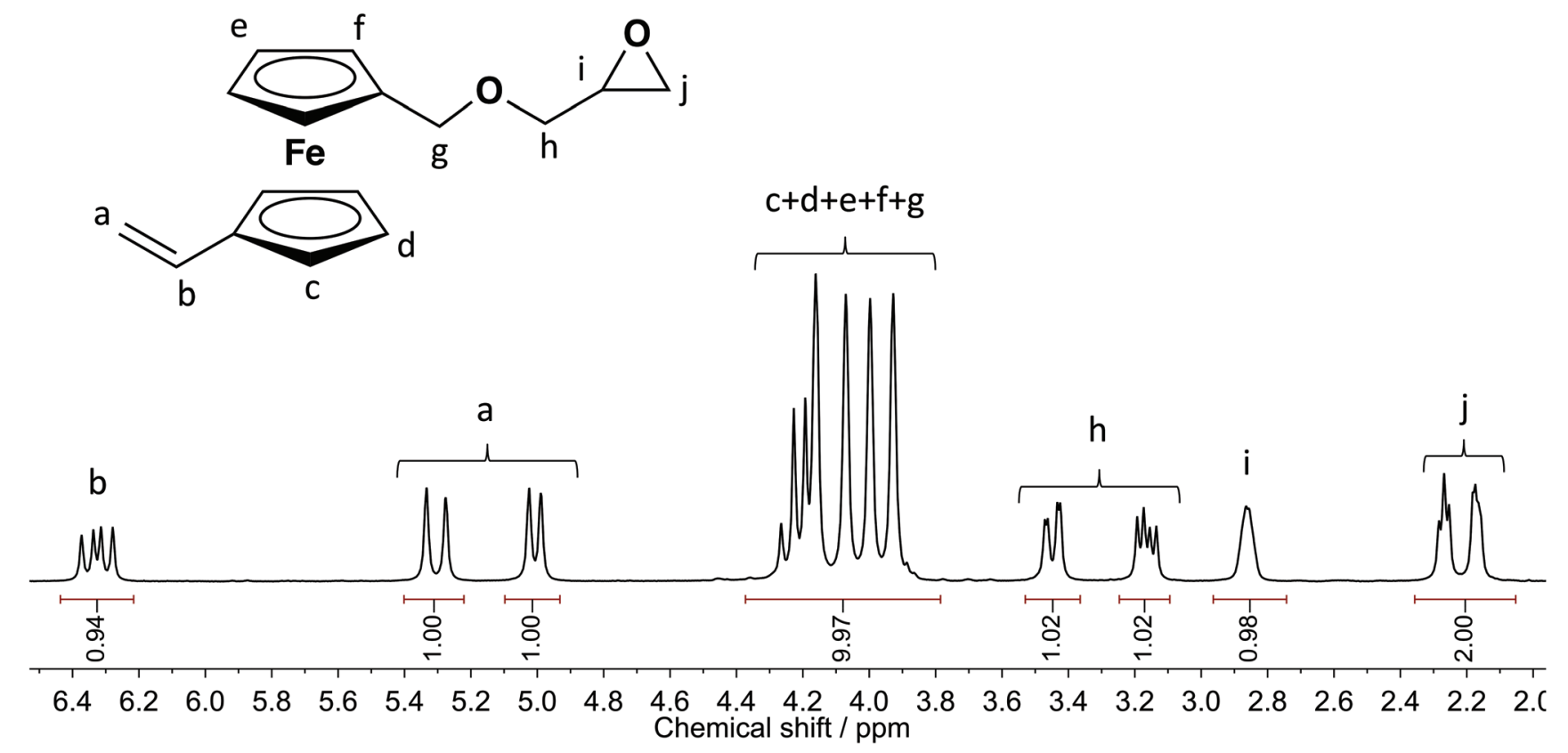

Fig. 2 Detailed assignment of ${ }^{1} \mathrm{H}$ NMR resonances of vinyl ferrocenyl glycidyl ether (3) (benzene- $d_{6}, 300 \mathrm{MHz}, 298 \mathrm{~K}$ ).

aldehyde ferrocene (5), was then reduced with sodium borohydride to 1-vinyl-1'-hydroxymethyl ferrocene (6). 6 was then converted to vinyl ferrocenyl glycidyl ether (3) via a nucleophilic substitution with epichlorohydrin under phase transfer catalysis, similar to the synthetic protocols of other previously described glycidyl ethers (GEs). ${ }^{28,29}$

The monomer was obtained as dark orange liquid in overall good yields and purified by column chromatography. Fig. 2 shows the ${ }^{1} \mathrm{H}$ NMR spectrum of 3 in benzene- $d_{6} ;{ }^{13} \mathrm{C}$ (Fig. S1 $\dagger$ ), ${ }^{13} \mathrm{C}$ DEPT (Fig. S2†), HSQC (Fig. S3†), HMBC (Fig. S4†) and COSY (Fig. S5†) NMR spectra with the respective assignments can also be found in the ESI $\dagger$ proving the signal assignments.

The free radical polymerization of 3 was carried out with 2,2'-azobis(2-methylpropionitrile) (AIBN) as the initiator in tetrahydrofuran (THF) at $80^{\circ} \mathrm{C}$ with a initiator: monomer ratio is $1: 60$. The resulting polymer (polyalkylene:P[VfcGE], P1) has a monomodal molecular weight distribution with a molecular weight dispersity of $D=1.83$ (Fig. 3), whereas a small elution peak for the monomer is present. The apparent molecular weight was determined to be $6000 \mathrm{~g} \mathrm{~mol}^{-1}$ from size exclusion chromatography (SEC) in THF vs. polystyrene (PS) standards. The molecular weight determined from matrix-assisted laser desorption/ionization time-of-flight mass spectrometry (MALDI ToF MS) is in good agreement with the results from the SEC measurements, which is shown in Fig. S6† and also confirms the repeating unit of VfcGE with a molecular weight of $298.16 \mathrm{~g} \mathrm{~mol}^{-1}$.

The homopolymer was also characterized by ${ }^{1} \mathrm{H}$ NMR spectroscopy. The spectrum in Fig. S7† shows broad polymeric resonances and all signals can be assigned to the polyalkylene:VfcGE homopolymer. The protons of the polyethylene backbone are detected between 1.0 and $2.4 \mathrm{ppm}$. The

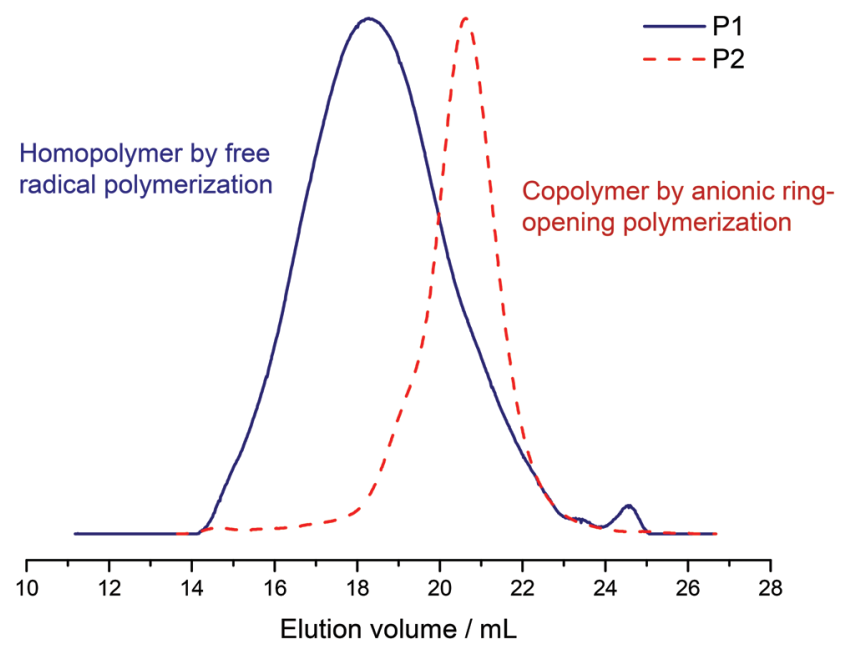

Fig. 3 SEC traces of P1 (THF, RI detection, $1 \mathrm{~mL} \mathrm{~min}^{-1}$ ) and P2 (DMF, RI detection, $1 \mathrm{~mL} \mathrm{~min}{ }^{-1}$ ).

epoxide protons can be detected in the region from 2.5 to $3.6 \mathrm{ppm}$ and overlap with the aromatic ferrocene protons from 3.6 to $4.8 \mathrm{ppm}$ (detailed peak assignment can be found in the ESI† Fig. S7).

The anionic ring-opening copolymerization of $\mathrm{VfcGE}$ and EO was carried out similar to previous works on EO copolymerizations. ${ }^{21,30,31}$ The copolymerization was initiated by the cesium salt of 2-benzyloxyethanol in a mixture of THF : DMSO (ratio $100: 1$ ), whereas dimethyl sulfoxide (DMSO) increase the polarity of the solvent mixture and therefore the solvation of the cesium cation. The polymerization was allowed to proceed for $12-24 \mathrm{~h}$ at $60{ }^{\circ} \mathrm{C}$ to reach complete conversion. All copoly- 
Table 1 Characterization data for polyalkylene:VfcGE homopolymer and P[VfcGE-co-EO] copolymers

\begin{tabular}{|c|c|c|c|c|c|c|}
\hline No. & Sum & $\begin{array}{l}\text { VfcGE } \\
(\mathrm{mol} \%)\end{array}$ & $\begin{array}{l}M_{\mathrm{n}}{ }^{a} \\
\left(\mathrm{~g} \mathrm{~mol}^{-1}\right)\end{array}$ & $\begin{array}{l}M_{\mathrm{n}}{ }^{b} \\
\left(\mathrm{~g} \mathrm{~mol}^{-1}\right)\end{array}$ & $\begin{array}{l}M_{\mathrm{n}}{ }^{c} \\
\left(\mathrm{~g} \mathrm{~mol}^{-1}\right)\end{array}$ & $\nexists^{c}$ \\
\hline P1 & Polyalkylene:VfcGE & 100 & - & - & 6000 & 1.83 \\
\hline P3 & $\mathrm{BnO}\left[\mathrm{P}\left(\mathrm{VfcGE}_{7}-c o-\mathrm{EO}_{70}\right)\right]$ & 8.8 & 7100 & 5200 & 1700 & 1.11 \\
\hline $\mathbf{P 4}$ & $\mathrm{BnO}\left[\mathrm{P}\left(\mathrm{VfcGE}_{14}-c o-\mathrm{EO}_{75}\right)\right]$ & 15.4 & 8400 & 7500 & 1800 & 1.14 \\
\hline
\end{tabular}

${ }^{a}$ Theoretical molecular weight according to initiator concentration. ${ }^{b} M_{\mathrm{n}}$ determined from ${ }^{1} \mathrm{H}$ NMR by end group analysis. ${ }^{c} M_{\mathrm{n}}$ determined via SEC in DMF vs. PEG (for P2, P3 and P4) and in THF $v s$. PS (in the case of P1) standards, $D=M_{\mathrm{w}} / M_{\mathrm{n}}$.

mers synthesized exhibited narrow molecular weight distributions $(D \leq 1.14)$ and monomodal SEC traces (in dimethylformamide (DMF) vs. polyethylene glycol (PEG) standards; Fig. 3), which is important since side reactions at the functional double bonds are conceivable and this proves the stability of the vinyl group in the side chain under the polymerization conditions. Copolymers with a maximum of $15.4 \mathrm{~mol} \%$ were synthesized to generate water-soluble materials (Table 1).

The absolute molecular weights of the copolymers as well as the comonomer content from the anionic ROP can be determined by ${ }^{1} \mathrm{H}$ NMR spectroscopy (Fig. S8 $\dagger$ ) and are in good agreement with the theoretical values. The methylene group and aromatic resonances of the initiator (at 4.34 and $7.31 \mathrm{ppm}$ ) can be used as reference signals and are compared to the polyether backbone between 3.68 and $3.45 \mathrm{ppm}$ and the signals of the vinyl group at 4.95-5.43 ppm and 6.27-6.47 ppm and cyclopentadienyl (cp) rings of fc at 4.02-4.29 (detailed peak assignment can be found in the ESI $\dagger$ Fig. S8). The incorporation of both comonomers was also confirmed by MALDI ToF MS (Fig. S9 $\uparrow$ ): a linear combination of the monomer masses of both repeating units can be detected in the spectrum and are marked with arrows.

Functionalization and materials properties of P[VfcGE-coEO] copolymers. The reaction between olefins and thiols is often used for polymer post-modification and was conducted with several vinyl-functionalized polymers before. ${ }^{32}$ The application of the radical thiol-ene addition allows the introduction of functional groups into the organometallic polyether that would not sustain the conditions of an anionic ROP. Thus, the pendant vinyl groups of the P[VfcGE-co-EO] copolymers were post-modified with 3-mercaptopropionic acid and AIBN as the respective initiator at $80{ }^{\circ} \mathrm{C}$ in THF (Scheme 3) to induce an additional pH-responsive behavior into the copolymers.
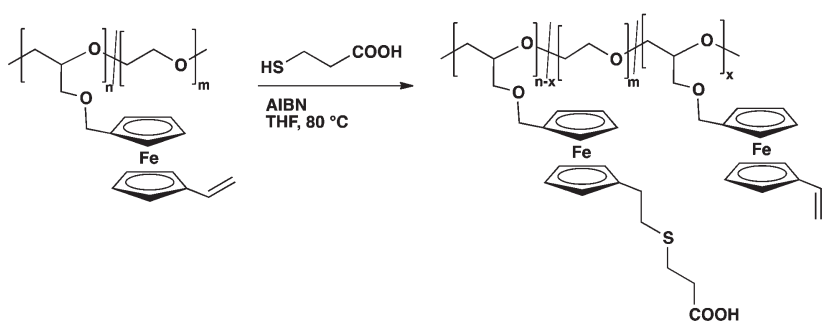

Scheme 3 Functionalization of P[VfcGE-Co-EO] copolymer with 3-mercaptopropionic acid.
A comparison of the ${ }^{1} \mathrm{H}$ NMR spectra before and after the functionalization is depicted in Fig. 4. It is noticeable that the protons of the vinyl groups, which appear in the range from 5.0 to $6.5 \mathrm{ppm}$, vanish and instead new signals for the ethylene linkage between ferrocene and the sulfur center appear at 3.0 to $2.6 \mathrm{ppm}$; less than $10 \%$ of the vinyl groups remain un-functionalized under these conditions.

Lower critical solution temperature (LCST) behavior. Copolymers of EO and hydrophobic comonomers exhibit a tunable thermoresponsive behavior depending on the amount and type of the comonomer. The cloud point temperature can be varied over a broad temperature range (typically over the whole range of liquid water, viz. $0-100^{\circ} \mathrm{C}$ ). The LCST can be lowered by increasing the amount of the hydrophobic comonomer or by increasing its hydrophobicity. As previously reported for poly(ferrocenyl glycidyl ether-co-ethylene oxide) (P[fcGE-coEO]) copolymers ${ }^{21}$ we have also detected thermoresponsive behavior for the P[VfcGE-co-EO] copolymers, as expected. The $\mathrm{P}[\mathrm{VfcGE}-\mathrm{co}-\mathrm{EO}]$ copolymers with more than $15.4 \mathrm{~mol} \% 3$ incorporated are water-insoluble, which is the reason, why copolymers with higher VfcGE contents or even homopolymers were not synthesized. An interesting feature of these organometallic copolymers is the tunable cloud point by partial or complete oxidation of the ferrocene moieties to the ferrocenium ions as demonstrated for the $\mathrm{P}\left[\mathrm{fcGE}-\mathrm{co}\right.$-EO] copolymers previously. ${ }^{21}$ Turbidity measurements of $\mathbf{P 2}$ and $\mathbf{P 3}$ are shown in Fig. 5. P3

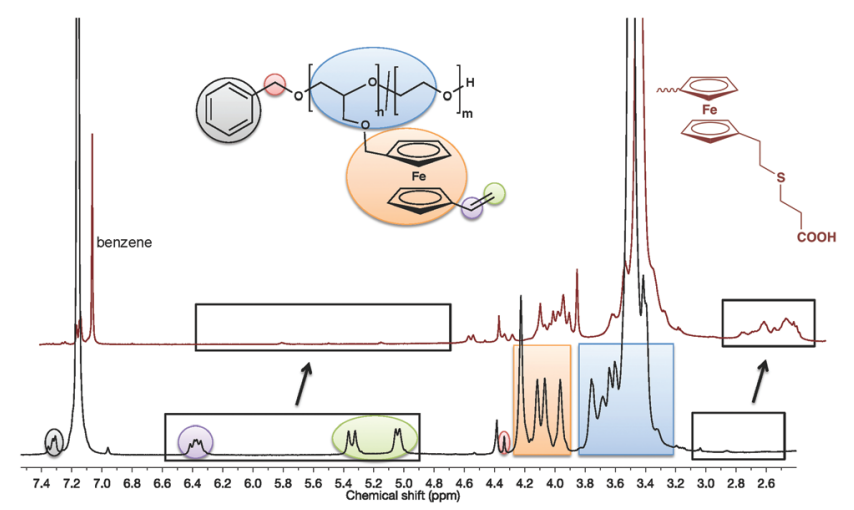

Fig. 4 Functionalization of P[VfCGE-co-EO] (P2, before functionalization, bottom; and P2', after functionalization, top) with 3-mercaptopropionic acid monitored by ${ }^{1} \mathrm{H}$ NMR spectroscopy (benzene- $d_{6}$, $400 \mathrm{MHz}, 298 \mathrm{~K})$. 


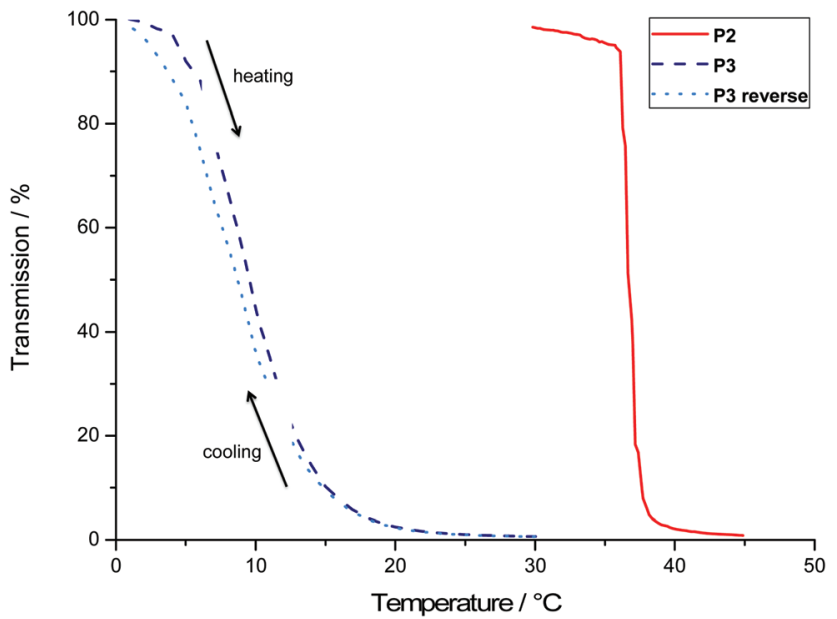

Fig. 5 Turbidity measurements of P2 and P3 $(\lambda=500 \mathrm{~nm}$; heat rate $=$ $1{ }^{\circ} \mathrm{C} \mathrm{min}^{-1}$ ) and the reversed measurement for $\mathrm{P} 3$ (cooling rate $=$ $\left.1^{\circ} \mathrm{C} \min ^{-1}\right)$.

with $8.8 \mathrm{~mol} \%$ VfcGE shows a cloud point temperature of $9^{\circ} \mathrm{C}$ while P2 with only 4.8 mol\% VfcGE exhibits a lower solubility limit at $37^{\circ} \mathrm{C}$. The cooling curve for P3 is also shown in Fig. 5, indicating a low hysteresis with a shifted cloud point towards lower temperatures, whereas the hysteresis is less than $1^{\circ} \mathrm{C}$.

In contrast to the $\mathrm{P}$ [fcGE-co-EO] copolymers, the novel $\mathrm{P}$ [VfcGE-co-EO] allow further chemical tuning of the cloud point temperature by functionalization of the pendant vinyl groups: hydrophilic groups are introduced via thiol-ene addition as described above. The 3-mercaptopropionic acid-functionalized copolymer (P2') shows an increased cloud point temperature due to the increased hydrophilicity of the polymer. The cloud point temperature of $\mathbf{P 2} \mathbf{2}^{\prime}$ at $\mathrm{pH} 3$ was determined to be $62^{\circ} \mathrm{C}$ (Fig. 6). Interestingly, the copolymer is water-

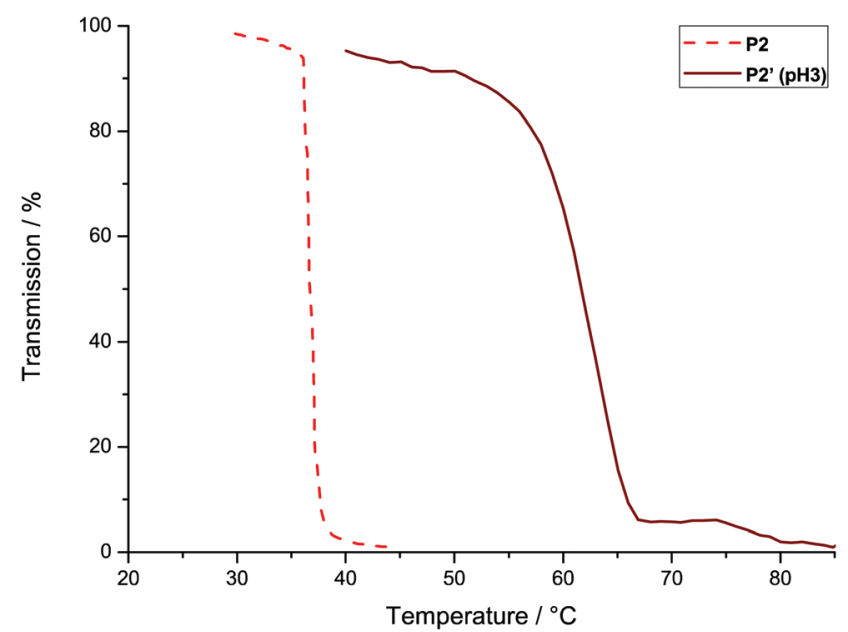

Fig. 6 Comparison of the turbidity measurements of $\mathbf{P 2}$ (at $\mathrm{pH}=7$ ) and post-modified $\mathrm{P} 2$ bearing carboxylic acid side chains (i.e. $\mathrm{P} 2$ ', at $\mathrm{pH}=3$ ), $\lambda=500 \mathrm{~nm}$; heat rate $=1{ }^{\circ} \mathrm{C} \mathrm{min}^{-1}$. soluble over the whole temperature range at pH-values higher than 3 due to (partial) deprotonation of the pendant carboxylic acid groups. Also, slow degradation of ferrocene under more acidic conditions limits the application to $\mathrm{pH}$ values of $c a .3$.

Nanoparticle formation from polyalkylene:VfcGE. The pendant groups of P1 were used to generate nanoparticles by the efficient nucleophilic ring-opening of epoxides with amines. ${ }^{33}$ In order to take advantage of the numerous epoxides attached to fc, redox-responsive nanoparticles have been synthesized. Such nanoparticle systems are interesting for delivery or self-healing applications as demonstrated previously. ${ }^{34,35}$ The hydrophobic P1 can be reacted in a miniemulsion polyaddition with polyfunctional, water-soluble amines. We chose bovine serum albumin (BSA), a $66 \mathrm{kDa}$ protein with 59 lysine units as an example for a biomolecule, capable of reacting with $\mathbf{P 1}$ to generate potentially biodegradable and redoxresponsive nanocarriers. Nanoparticles were prepared by interfacial nucleophilic addition from the protein dissolved in stable water-droplets, which were dispersed in toluene containing the ferrocene-containing polyepoxide by adapting a previously published protocol. ${ }^{36}$ The resulting particles showed a size of ca. $309 \mathrm{~nm}$ from dynamic light scattering (DLS). Imaging of the nanoparticles by TEM shows spherical structures with diameters much smaller than those determined by DLS (Fig. 7). This is probably caused by drying effects, as the polymer chains collapse during the process, indicating the formation of a cross-linked nanoparticle based on the protein and the ferrocene-containing cross-linker. After redispersion in water, the size of the particles decreases to $92 \mathrm{~nm}$ as determined by DLS, because the chains of $\mathbf{P 1}$ are not soluble in water leading to shrinkage of the nanoparticles.

To show the redox-responsivity of these nanoparticles, the ferrocene units of P1 were oxidized with hydrogen peroxide under slightly acidic conditions. After oxidation, no precise size determination by DLS measurements was possible due to the formation of large aggregates, probably due to electrostatic interactions. TEM imaging (see Fig. 7) shows no distinct nanoparticles after oxidation, but the formation of supramolecular aggregates. ${ }^{37}$ This strategy could be further used for a redoxcontrolled gelators, which is currently under investigation in our group.
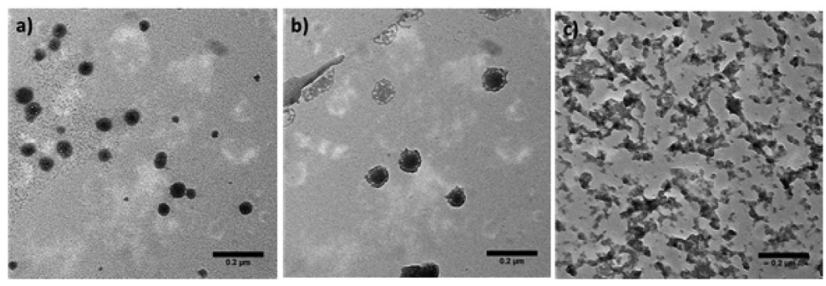

Fig. 7 TEM images of cross-linked polyalkylene:VfcGE-BSA nanoparticles drop-cast from the toluene dispersion (a), drop-cast from the aqueous dispersion (b), and the formation of a gel after oxidation of the aqueous dispersion (c). 


\section{Conclusion}

Both of ferrocene's cyclopentadienyl ligands have been used as handles for the attachment of polymerizable groups. The first orthogonal ferrocene monomer, namely vinyl ferrocene glycidyl ether (VfcGE), has been synthesized and polymerized via two different polymerization techniques: on the one hand the vinyl group enables the radical polymerization, and on the other the epoxide enables the living oxyanionic ring-opening polymerization. The two monomer sites polymerize selectively without any influence on the other functionality. In addition VfcGE could also serve as a novel organometallic/redox-responsive linker molecule for many other applications.

After polymerization, however, multifunctional organometallic (co-)polymers are obtained. They can be easily postmodified without previous protection and deprotection steps. VfcGE combines two side-chain monomers, the classical vinylferrocene and the rather new ferrocenyl glycidyl ether in a novel bifunctional monomer. Radical polymerization of the vinyl group produces redox-responsive polyepoxides that have been utilized for the formation of protein nanoparticles, but may find further application in epoxy resins with additional redox potential. When the epoxide in $\mathbf{1}$ is polymerized by anionic polymerization, polyethers with pendant vinyl groups are generated. By copolymerization of $\mathbf{1}$ with ethylene oxide, water-soluble poly(ethylene glycol)-derivatives are obtained exhibiting cloud point temperatures depending on the amount and oxidation state of ferrocene within the polymer. Further tuning of the cloud point temperature was achieved by chemical functionalization of the pendant vinyl groups of the $\mathrm{P}$ [VfcGE-co-EO] copolymers: functionalization with 3-mercaptopropionic acid further introduces $\mathrm{pH}$-responsibility for the cloud point temperatures. We believe that this new monomer opens various potential applications for ferrocene-containing polymers with additional functionalities, for example for advanced sensors or the formation of biomimetic, redoxcontrolled nanoparticles.

\section{Experimental}

\section{Instrumentation}

${ }^{1} \mathrm{H}$ NMR spectra (300, 400 and $500 \mathrm{MHz}$ ) and ${ }^{13} \mathrm{C}$ NMR spectra (75.5, and $101 \mathrm{MHz}$ ) were recorded using a Bruker AC300, a Bruker AMX400 and Bruker Avance 500. All spectra were referenced internally to residual proton signals of the deuterated solvent.

For size exclusion chromatography (SEC) measurements in DMF (containing $0.25 \mathrm{~g} \mathrm{~L}^{-1}$ of lithium bromide as an additive) an Agilent 1100 Series was used as an integrated instrument, including a PSS HEMA column (106/105/104 $\left.\mathrm{g} \mathrm{mol}^{-1}\right)$, a UV detector (275 $\mathrm{nm})$, and a RI detector at a flow rate of $1 \mathrm{~mL} \min ^{-1}$ at $50{ }^{\circ} \mathrm{C}$. Calibration was carried out using PEG standards provided by Polymer Standards Service.

SEC in THF was performed on an instrument consisting of a Waters 717 plus auto sampler, a TSP Spectra Series P 100 pump and a set of three PSS SDV columns $\left(10^{4} / 500 / 50 \AA\right)$. Signal detection occurred by a UV (TSP Spectra System UV 2000, $254 \mathrm{~nm}$ ), and a refractive index (Agilent 1260) detector. Calibration was carried out using PS standards provided by Polymer Standards Service.

Matrix-assisted laser desorption/ionization time-of-flight (MALDI-ToF) measurements were performed using a shimadzu Axima CFR MALDI-TOF mass spectrometer, employing DCTB (trans-2-[3-(4-tert-butylphenyl)-2-methyl-2-propenylidene] malononitrile) as a matrix ( $5 \mathrm{mg} \cdot \mathrm{mL}^{-1}$ in THF).

For electron microscopy measurements $3 \mu \mathrm{L}$ sample were placed on a carbon-coated copper grid. TEM measurements were carried out on a JEOL 1400 at a voltage of $120 \mathrm{kV}$ and images were taken with a GATAN Ultrascan 1000 CCD-camera.

Turbidity measurements were performed in deionized water and observed by optical transmittance of a light beam $(\lambda=500 \mathrm{~nm} ; 50 \%)$ through a $1 \mathrm{~cm}$ sample quartz cell. The measurements were performed in a Jasco V-630 photospectrometer with a Jasco ETC-717 Peltier element. The intensity of the transmitted light was recorded versus the temperature of the sample cell. The heating/cooling rate was $1^{\circ} \mathrm{C} \mathrm{min}^{-1}$, and values were recorded every $0.1^{\circ} \mathrm{C}$.

Dynamic light scattering (DLS) were performed on diluted dispersions with a Nicomp ${ }^{\mathrm{TM}} 380$ Submicron Particle Sizer (PSS-Nicomp) at an angle of $90^{\circ}$ or on an ALV spectrometer consisting of a goniometer and an ALV-5004 multiple-tau fulldigital correlator (320 channels) which allows measurements over an angular range from $20^{\circ}$ to 150 . A He-Ne Laser (wavelength of $632.8 \mathrm{~nm}$ ) is used as light source.

\section{Reagents}

Solvents and reagents were purchased from Acros Organics, Sigma-Aldrich or Fluka and used as received, unless otherwise stated. Chloroform- $d_{1}$ and benzene- $d_{6}$ were purchased from Deutero GmbH. EO was freshly distilled before use. 1-vinyl-1'carboxaldehyde (5) was synthesized starting from ferrocene as described in literature. ${ }^{27}$

\section{Synthesis of 1-vinyl-1'-hydroxymethyl ferrocene (6)}

$1.85 \mathrm{~g}$ 1-vinyl-1'-carboxaldehyde ferrocene $(5 ; 7.7 \mathrm{~mol})$ were dissolved in methanol. $120 \mathrm{mg}$ sodium borohydride $(3.1 \mathrm{mmol}$, 0.4 eq.) were added in small portions under stirring at room temperature. The mixture was stirred until all sodium borohydride was dissolved (approx. $30 \mathrm{~min}$ ). Distilled water was added and the reaction mixture was extracted three times with diethyl ether. The solvent was removed at reduced pressure and the product was obtained as yellow solid $(1.82 \mathrm{~g}$, $7.53 \mathrm{mmol}$ ) and was pure enough for further reactions. Yield: 98\%. ${ }^{1} \mathrm{H}$ NMR $\left(\mathrm{C}_{6} \mathrm{D}_{6}, 300 \mathrm{MHz}, 298 \mathrm{~K}\right): \delta(\mathrm{ppm})=6.37-6.24$ (dd, $1 \mathrm{H}, \mathrm{H}_{2} \mathrm{C}=\mathrm{CH}$-fc, $J=17.5,10.7 \mathrm{~Hz}$ ), 5.32-5.23 (dd, $1 \mathrm{H}$, $\mathrm{H} H \mathrm{C}=\mathrm{CH}-\mathrm{fc}, J=17.5,1.6 \mathrm{~Hz}), 5.00-4.94(\mathrm{dd}, 1 \mathrm{H}, H \mathrm{HC}=\mathrm{CH}-$ fc, $J=10.8,1.5 \mathrm{~Hz}), 4.22-4.15\left(\mathrm{~d}, 2 \mathrm{H}, \mathrm{fc}-\mathrm{CH}_{2}-\mathrm{OH}, J=4.1 \mathrm{~Hz}\right.$ ), 4.15-3.87 (m, 8H, $f c)$. (Detailed peak assignment can be found in the ESI† Fig. S10.) 


\section{Synthesis of vinyl ferrocenyl glycidyl ether (VfcGE, 3)}

A mixture of a $8 \mathrm{~mL} 50 \%$ aqueous $\mathrm{KOH}$ solution, $0.57 \mathrm{~mL}$ epichlorohydrin $(7.3 \mathrm{mmol})$ and $100 \mathrm{mg}$ tetrabutylammonium bromide as phase transfer catalyst cooled to $c a .0{ }^{\circ} \mathrm{C}$ with an ice bath. $1.64 \mathrm{~g}$ ( $6.8 \mathrm{mmol})$ 1-vinyl-1'-hydroxymethyl ferrocene (6) were dissolved in benzene and added drop-wise to the reaction mixture. The mixture was rapidly stirred and allowed to warm up to room temperature. After $24 \mathrm{~h}$ ice was added and the mixture extracted with diethyl ether. After washing with brine, the solvent was removed at reduced pressure. The crude product was purified by column chromatography over silica using a mixture of ethyl acetate and petroleum ether $(3: 7)$ as eluent. The pure product was obtained as a dark orange liquid. Yield: $83 \% .{ }^{1} \mathrm{H}$ NMR $\left(\mathrm{C}_{6} \mathrm{D}_{6}, 300 \mathrm{MHz}, 298 \mathrm{~K}\right): \delta(\mathrm{ppm})=$ 6.44-6.22 (dd, $1 \mathrm{H}, \mathrm{H}_{2} \mathrm{C}=\mathrm{CH}-\mathrm{fc}, J=17.5,10.7 \mathrm{~Hz}$ ), 5.38-5.23 (d, $1 \mathrm{H}, \mathrm{H} H \mathrm{C}=\mathrm{CH}-\mathrm{fc}, J=17.0 \mathrm{~Hz}$ ), $5.09-4.94(\mathrm{~d}, 1 \mathrm{H}, H \mathrm{HC}=\mathrm{CH}-\mathrm{fc}$, $J=10.6 \mathrm{~Hz}), 4.35-3.80\left(\mathrm{~m}, 10 \mathrm{H}, f c-\mathrm{CH}_{2}-\mathrm{O}\right), 3.52-3.38(\mathrm{dd}, 1 \mathrm{H}$, fc- $\left.\mathrm{CH}_{2} \mathrm{OCHH}, J=11.4,3.0 \mathrm{~Hz}\right), 3.25-3.10(\mathrm{dd}, 1 \mathrm{H}, \mathrm{fc}-$ $\left.\mathrm{CH}_{2} \mathrm{OCH} H, J=11.4,5.9 \mathrm{~Hz}\right), 2.92-2.80(\mathrm{~m}, 1 \mathrm{H}$, epoxide $\mathrm{C} H)$, 2.32-2.12 (m, 2H, epoxide $\left.\mathrm{CH}_{2}\right)$. (Detailed peak assignment in Fig. 2; for additional characterization data, see ESI $\dagger$ Fig. S1 $\left({ }^{13} \mathrm{C}\right)$, S2 $\left({ }^{13} \mathrm{C}\{\mathrm{H}\}\right.$ DEPT), S3 (HSQC), S4 (HMBC) and $\mathrm{S} 5$ (COSY).)

\section{General procedure for the copolymerization of VfcGE and EO (P2, P3, P4): P[EO-co-VfcGE]}

$17.6 \mathrm{mg}$ (0.116 mmol) 2-(benzyloxy)ethanol and $17.5 \mathrm{mg}$ ( $0.104 \mathrm{mmol}, 0.9$ eq.) of cesium hydroxide monohydrate were placed in a $100 \mathrm{~mL}$ Schlenk flask and suspended in $10 \mathrm{~mL}$ of benzene. The mixture was stirred at $60{ }^{\circ} \mathrm{C}$ under an argon atmosphere for $1 \mathrm{~h}$ and evacuated at $60{ }^{\circ} \mathrm{C}\left(10^{-2} \mathrm{mbar}\right)$ for $12 \mathrm{~h}$ to remove benzene and water (as an azeotrope with benzene) to generate the corresponding cesium alkoxide. Subsequently, approx. $20 \mathrm{~mL}$ of dry THF were cryo-transferred into the Schlenk flask. $0.5 \mathrm{~mL}(11.0 \mathrm{mmol}) \mathrm{EO}$ was cryo-transferred to a graduated ampule and then cryo-transferred into the reaction flask containing the initiator in THF. Then $170 \mathrm{mg}$ $(0.580 \mathrm{mmol}$; for a composition of $1: 19)$ of the second comonomer, VfcGE (3), was added via syringe in a $50 \mathrm{wt} \%$ solution in anhydrous DMSO. The reaction mixture was heated up to $60{ }^{\circ} \mathrm{C}$ and stirred for $12-24 \mathrm{~h}$ before the living chain ends were terminated with methanol. The copolymer solution was dried in vacuo and precipitated into cold diethyl ether. The copolymer was obtained as an orange to dark orange viscous material, the color strongly depending on fc content. Yields: $70-90 \% .{ }^{1} \mathrm{H}$ NMR $\left(\mathrm{C}_{6} \mathrm{D}_{6}, 400 \mathrm{MHz}, 298 \mathrm{~K}\right): \delta(\mathrm{ppm})=7.31(\mathrm{~m}$, $5 \mathrm{H}$, aromatic protons of initiator), 6.47-6.28 (dd, $\mathrm{H}_{2} \mathrm{C}=\mathrm{CH}$-fc), 5.41-4.96 (m, $\left.\mathrm{H}_{2} \mathrm{C}=\mathrm{CH}-\mathrm{fc}\right), 4.33$ (s, $2 \mathrm{H}$, aliphatic signals of initiator), 4.29-3.91 (m, $\left.f c-\mathrm{CH}_{2}-\mathrm{O}\right), 3.85-3.10$ (residual protons: PEO backbone, fc- $\mathrm{CH}_{2}-\mathrm{O}-\mathrm{CH}_{2}$-backbone).

\section{Procedure for the free radical polymerization of VfcGE: polyalkylene:VfcGE (P1)}

$100 \mathrm{mg}$ VfcGE (3) and 1,2 mg azobis(isobutyronitrile) (AIBN) were dissolved in $2 \mathrm{~mL}$ THF. After three freeze-pump-thaw cycles (to remove any oxygen from the system) the reaction mixture was heated to $80{ }^{\circ} \mathrm{C}$ and stirred for $12 \mathrm{~h}$. The reaction mixture was flushed with air and precipitated into cold methanol. The polymer was obtained as a yellow highly viscous liquid. Yield: $90 \% .{ }^{1} \mathrm{H}$ NMR $\left(\mathrm{C}_{6} \mathrm{D}_{6}, 400 \mathrm{MHz}, 298 \mathrm{~K}\right): \delta(\mathrm{ppm})=$ 5.0-3.5 (m, br, $\left.11 \mathrm{H}, \mathrm{fc}-\mathrm{H}, \mathrm{fc}-\mathrm{CH}_{2}-\mathrm{O}-\mathrm{CH} \mathrm{H}-\right)$, 3.5-3.25 (m, br, 1H, -O-CHH-epoxide), 3.25-3.00 (m, br, $1 \mathrm{H}, \mathrm{CH}$ of epoxide), 2.90-2.70 (m, br, $1 \mathrm{H}, \mathrm{CH}_{2}$ of epoxide), 2.70-2.45 (m, br, $1 \mathrm{H}$, $\mathrm{CH}_{2}$ of epoxide), $2.45-1.00$ (m, br, $3 \mathrm{H}$, polyalkylene backbone).

\section{Polymer modification via thiol-ene addition}

$100 \mathrm{mg}$ of the respective copolymer were dissolved in $5 \mathrm{~mL}$ THF and a 20 -fold molar excess $(156 \mathrm{mg}$ ) of 3-mercaptopropionic acid and $13.9 \mathrm{mg}$ ( 0.75 eq.) of AIBN with respect to the absolute number of vinyl groups, were added. After three freeze-pump-thaw cycles (to remove any oxygen from the system) the reaction mixture was heated to $80^{\circ} \mathrm{C}$ and stirred for $12 \mathrm{~h}$. The reaction mixture was dialyzed against methanol, using benzoylated tubings (MWCO $1000 \mathrm{~g} \mathrm{~mol}^{-1}$ ) over a period of $24 \mathrm{~h}$. Yield: $95 \% .{ }^{1} \mathrm{H}$ NMR $\left(\mathrm{C}_{6} \mathrm{D}_{6}, 400 \mathrm{MHz}, 298 \mathrm{~K}\right): \delta(\mathrm{ppm})=$ $7.31(\mathrm{~m}, 5 \mathrm{H}$, aromatic protons of initiator $), 4.33(\mathrm{~s}, 2 \mathrm{H}$, aliphatic signals of initiator), 4.29-3.91 (m, $\left.f c-\mathrm{CH}_{2}-\mathrm{O}\right), 3.85-3.10$ (residual protons: $\mathrm{PEO}$ backbone, fc- $\mathrm{CH}_{2}-\mathrm{O}-\mathrm{CH}_{2}$-backbone), $3.00-2.55$ (m, fc- $\left.\mathrm{CH}_{2}-\mathrm{CH}_{2}-\mathrm{S}\right)$.

\section{Polymer nanoparticle formation via nucleophilic ring-opening} of the pendant epoxides of P1 with amino-groups of BSA

$25 \mathrm{mg}$ bovine serum albumin (BSA) and $3.8 \mathrm{mg}$ sodium chloride were dissolved in $0.25 \mathrm{~g}$ Milli-Q water. Separately, $17.9 \mathrm{mg}$ polyglycerin-polyricinoleate (PGPR) as surfactant were dissolved in $4.2 \mathrm{~g}$ toluene by treatment in an ultrasound bath at $60{ }^{\circ} \mathrm{C}$ for 20 minutes and added drop-wise to the aqueous solution. After stirring for one hour at room temperature, the resulting macroemulsion was subjected to ultrasonication using a Branson W450-D Sonifier with a $1 / 8$ inch tip at $69 \%$ amplitude for 3 minutes ( 20 seconds pulse, 10 seconds pause) under ice-cooling. Separately, $5.4 \mathrm{mg}$ PGPR and $6.8 \mathrm{mg}$ of P1 were dissolved in $2.8 \mathrm{~g}$ toluene and added dropwise to the obtained emulsion. The reaction was carried out for $24 \mathrm{~h}$ at room temperature. The resulting dispersion was filtered to remove any aggregates. For purification the dispersion was centrifuged at $1163 \mathrm{rcf}$ for 20 minutes. After removing the supernatant, the particles were redispersed in an equivalent amount of fresh toluene. Centrifugation and redispersion steps were repeated once. For redispersion in water, $5 \mathrm{~g}$ of an aqueous solution of cetyltrimethylammonium chloride (CTMACl) (1 wt\%) were added dropwise to $1 \mathrm{~g}$ of the nanoparticle dispersion. After toluene evaporation the aqueous dispersion was dialyzed against Milli-Q water for $24 \mathrm{~h}$ to remove an excess of surfactant. For oxidation, $1 \mathrm{~mL}$ aqueous dispersion was mixed with $2.5 \mu \mathrm{L} 35 \% \mathrm{H}_{2} \mathrm{O}_{2}$ solution and $6 \mu \mathrm{L}$ $0.1 \mathrm{M} \mathrm{HCl}$. The nanoparticle dispersion was characterized by DLS and TEM at every step. 


\section{Acknowledgements}

F.R.W. thanks the Max Planck Graduate Center (MPGC) for support. The authors thank Prof. Dr Katharina Landfester (MPIP, Mainz) and Prof. Dr Holger Frey (JGU, Mainz) for support, Christine Rosenauer (MPIP, Mainz) for DLS measurements, Angelika Manhart (MPIP, Mainz), and Luka Decker (JGU, Mainz) for technical assistance.

\section{Notes and references}

1 A. Rabiee Kenaree, B. M. Berven, P. J. Ragogna and J. B. Gilroy, Chem. Commun., 2014, 50, 10714-10717.

2 S. P. Hendry, M. F. Cardosi, A. P. F. Turner and E. W. Neuse, Anal. Chim. Acta, 1993, 281, 453-459.

3 T. Soganci, D. O. Demirkol, M. Ak and S. Timur, RSC Adv., 2014, 4, 46357-46362.

4 R. Ayranci, D. O. Demirkol, M. Ak and S. Timur, Sensors, 2015, 15, 1389-1403.

5 A. Togni and T. Hayashi, Org. Synth., 1995, 3-172.

6 B. Wei, R. Vajtai, Y. Choi, P. Ajayan, H. Zhu and C. Xu, Nano Lett., 2002, 2, 1105-1107.

7 X. Zhang, A. Cao, B. Wei, Y. Li, J. Wei, C. Xu and D. Wu, Chem. Phys. Lett., 2002, 362, 285-290.

8 M. Kasper, K. Sattler, K. Siegmann and U. Matter, J. Aerosol Sci., 1999, 30, 217-225.

9 D. Scheid, C. Lederle, S. Vowinkel, C. G. Schäfer, B. Stühn and M. Gallei, J. Mater. Chem. C, 2014, 2, 2583-2590.

10 Z. M. Hudson and I. Manners, Science, 2014, 344, 482-483.

11 Z. M. Hudson, D. J. Lunn, M. A. Winnik and I. Manners, Nat. Commun., 2014, 5, 3372.

12 J. Zhang, Y. P. Chen, K. P. Miller, M. S. Ganewatta, M. Bam, Y. Yan, M. Nagarkatti, A. W. Decho and C. Tang, J. Am. Chem. Soc., 2014, 136, 4873-4876.

13 S. S. Braga and A. M. S. Silva, Organometallics, 2013, 32, 5626-5639.

14 G. R. Whittell and I. Manners, Adv. Mater., 2007, 19, 34393468.

15 D. A. Rider and I. Manners, Polym. Rev., 2007, 47, 165-195.

16 Y. Ni, R. Rulkens and I. Manners, J. Am. Chem. Soc., 1996, 118, 4102-4114.

17 F. Wurm, S. Hilf and H. Frey, Chem. - Eur. J., 2009, 15, 9068-9077.
18 F. S. Arimoto and A. C. Haven, J. Am. Chem. Soc., 1955, 77, 6295-6297.

19 C. G. Hardy, L. Ren, T. C. Tamboue and C. Tang, J. Polym. Sci., Part A: Polym. Chem., 2011, 49, 14091420.

20 C. U. Pittman, J. C. Lai, D. P. Vanderpool, M. Good and R. Prado, Macromolecules, 1970, 3, 746-754.

21 C. Tonhauser, A. Alkan, M. Schömer, C. Dingels, S. Ritz, V. Mailänder, H. Frey and F. R. Wurm, Macromolecules, 2013, 46, 647-655.

22 A. Alkan, A. Natalello, M. Wagner, H. Frey and F. R. Wurm, Macromolecules, 2014, 47, 2242-2249.

23 H. Hirata, Y. Iwama, S. Kuroda, T. Fukuda and T. Hagiwara, React. Funct. Polym., 2009, 69, 170-175.

24 F. Jing and M. A. Hillmyer, J. Am. Chem. Soc., 2008, 130, 13826-13827.

25 S. Kanoh, T. Nishimura and T. Tsuchida, Macromol. Chem. Phys., 2001, 202, 2489-2503.

26 A.-L. Brocas, C. Mantzaridis, D. Tunc and S. Carlotti, Prog. Polym. Sci., 2013, 38, 845-873.

27 K. P. Barry and C. Nataro, Inorg. Chim. Acta, 2009, 362, 2068-2070.

28 C. Mangold, C. Dingels, B. Obermeier, H. Frey and F. Wurm, Macromolecules, 2011, 44, 6326-6334.

29 F. Wurm, J. Nieberle and H. Frey, Macromolecules, 2008, 41, 1909-1911.

30 C. Mangold, F. Wurm, B. Obermeier and H. Frey, Macromolecules, 2010, 43, 8511-8518.

31 B. Obermeier, F. Wurm and H. Frey, Macromolecules, 2010, 43, 2244-2251.

32 K. Günay, P. Theato and H.-A. Klok, J. Polym. Sci., Part A: Polym. Chem., 2013, 51, 1-28.

33 X. Jing, Y. Liu, Y. Liu, Z. Liu and H. Tan, J. Appl. Polym. Sci., 2014, 131, 40835.

34 K. Landfester, Angew. Chem., Int. Ed., 2009, 48, 44884507.

35 R. H. Staff, M. Gallei, M. Mazurowski, M. Rehahn, R. Berger, K. Landfester and D. Crespy, ACS Nano, 2012, 6, 9042-9049.

36 D. Yiamsawas, G. Baier, E. Thines, K. Landfester and F. R. Wurm, RSC Adv., 2014, 4, 11661-11663.

37 T. Rudolph, A. Nunns, A. M. Schwenke and F. H. Schacher, Polym. Chem., 2015, 6, 1604-1612. 